\title{
PENENTUAN SIMPANG BERSINYAL RAWAN KECELAKAAN UNTUK IDENTIFIKASI AWAL TERHADAP POTENSI RED LIGHT RUNNING (RLR) DI BANDA ACEH
}

\section{Determination of Accident Prone Signalized Intersection for Early Identification of Potential Red Light Running (RLR) in Banda Aceh}

\author{
Sofyan M. Saleh \\ Jurusan Teknik Sipil \\ Universitas Syiah Kuala \\ Jl. Syekh Abdurauf As Sinkili \\ No.7 Banda Aceh, Aceh \\ sofyan.saleh@unsyiah.ac.id
}

\author{
Sugiarto Sugiarto \\ Jurusan Teknik Sipil \\ Universitas Syiah Kuala \\ J1. Syekh Abdurauf As Sinkili \\ No.7 Banda Aceh, Aceh \\ sugiarto@unsyiah.ac.id
}

\author{
Endang Handayani \\ Jurusan Teknik Sipil \\ Universitas Syiah Kuala \\ Jl. Syekh Abdurauf As Sinkili \\ No.7 Banda Aceh, Aceh \\ endangh606@gmail.com
}

\begin{abstract}
Red Light Running (RLR) is the leading cause of traffic accidents at signal intersections in various countries including Indonesia. The main reason is the existence of conflicts caused by drivers behavioral factors who are not obedient or understand about signaling operations. RLR is the most dangerous driver's behavior in a signal intersection, where the driver fails to comply with signaling rules at the intersection so that the conflict occurs. To assess the behavior of the RLR, the first step is to identify the signaled intersections that are most prone to accidents. This is needed to eliminate the location of study or handling due to limited time and costs. The methodology used to determine accident-prone locations is based on the Highway Safety Improvement Program in the Highway Safety Manual (HSM, 2010), namely planning component consisting of data collection and identification of accident-prone areas in signal intersections. Using accident data of 20132015, and by combining three methods of analysis such as frequency, accident rate, and equivalent property damage only methods then three most accident-prone signal intersections are determined and prioritized for in-depth study of RLR behavior analysis.
\end{abstract}

Keywords: Red Light Running, behaviors, signalized intersection, identification, HSM.

\begin{abstract}
Abstrak
Red Light Running (RLR) adalah penyebab utama kecelakaan lalu lintas pada simpang bersinyal di berbagai negara termasuk Indonesia. Penyebab utamanya adalah adanya konflik yang diakibatkan oleh faktor perilaku pengemudi yang tidak patuh atau paham tentang pengoperasian persinyalan. RLR merupakan perilaku pengemudi yang paling berbahaya pada simpang bersinyal, dimana pengemudi gagal mematuhi peraturan persinyalan pada simpang sehingga konflik terjadi. Untuk mengkaji perilaku pada RLR perlu dilakukan langkah awal yaitu identifikasi simpang bersinyal yang paling rawan terhadap kecelakaan. Hal ini diperlukan untuk mengeliminasi lokasi kajian atau penanganan akibat keterbatasan waktu dan biaya. Metodologi yang digunakan untuk penentuan lokasi rawan kecelakaan dilakukan mengacu pada Highway Safety Improvement Program di dalam Highway Safety Manual (HSM, 2010), yaitu planning component yang terdiri dari pengumpulan data dan identifikasi daerah rawan kecelakaan pada simpang bersinyal. Menggunakan data kecelakaan tahun 2013-2015 dengan mengombinasikan tiga metode analisis yaitu metode frekuensi, tingkat kecelakaan dan ekuivalensi kerugian harta benda (EPDO) ditentukan tiga simpang bersinyal yang paling rawan kecelakaan dan diprioritaskan untuk dilakukan kajian mendalam terhadap perilaku pelanggaran RLR.
\end{abstract}

Kata kunci: Red Light Running, perilaku, simpang bersinyal, identifikasi, HSM. 


\section{PENDAHULUAN}

Tingginya permintaan perjalanan dan ketergantungan masyarakat pada moda transportasi pribadi (sepeda motor dan mobil) mengakibatkan kompleksnya sistem transportasi di perkotaan. Berdasarkan data Sistem Administrasi Manunggal Satu Atap (Samsat) Aceh, pertambahan kendaraan baru mencapai 113.206 unit ditahun 2015. Ketergantungan moda pribadi menyebabkan berbagai permasalahan serius dalam sistem lalu lintas seperti kemacetan, kecelakaan dan dampak lingkungan (Saleh dkk., 2015; Sugiarto dkk., 2013). Kecelakaan lalu lintas menjadi salah satu isu yang sangat krusial selain kemacetan dan dampak lingkungan. Kecelakaan lalu lintas tidak hanya terjadi pada ruas jalan namun juga pada persimpangan terutama simpang bersinyal. Pada simpang bersinyal pelanggaran pada saat sinyal merah (Red Light Running/RLR) menjadi salah satu faktor dominan penyebab kecelakaan. Persimpangan umumnya dirancang dengan tujuan mengurangi jumlah konflik pertemuan arus lalu lintas dan mengurangi konsentrasi pertemuan arus lalu lintas. Umumnya simpang bersinyal di Indonesia dioperasikan dengan sistem pre-timed signal dengan pembagian masing-masing fase disetiap lengan simpang. Seharusnya simpang dengan masing-masing fase per lengan tidak terjadi konflik akibat pertemuan arus lalu lintas dan mengakibatkan kecelakaan akibat pelanggaran lampu merah. Kecelakaan disimpang bersinyal banyak terjadi karena adanya konflik yang diakibatkan oleh faktor perilaku pengemudi yang tidak patuh atau paham tentang pengoperasian persinyalan.

Pelanggaran RLR merupakan bentuk pelanggaran yang paling banyak dijumpai pada simpang bersinyal dan menjadi salah satu faktor dominan penyebab kecelakaan lalu lintas di persimpangan. Kecelakaan akibat RLR telah berkontribusi paling banyak menyebabkan kecelakaan dengan kategori luka berat hingga kematian (Young dkk., 2013; Polders dkk., 2015; Jahangiri dkk., 2016; Ren dkk., 2016). Sebagai contoh, di Thailand pada Tahun 2015 dilaporkan 1702 kecelakaan lampu merah di persimpangan atau 1,96\% dari semua kecelakaan yang dilaporkan polisi disebabkan oleh pengemudi melanggar lampu merah (Kanitpong dkk., 2015; Jensupakarn dkk., 2018). Hal ini juga tercatat di Amerika Serikat, setidaknya 697 orang tewas dalam kecelakaan yang melibatkan RLR pada tahun 2013, sementara diperkirakan 127.000 orang terluka (McCarthy, 2015). Untuk mengurangi kecelakaan akibat RLR, sangat penting untuk fokus pada identifikasi lokasi simpang yang banyak terjadi kecelakaan RLR, bagaimana mengklasifikasi RLR, dan mengapa setiap jenis RLR bias terjadi. Jenis kecelakaan RLR dapat diklasifikasikan berdasarkan gerakan kendaraan masuk ke area konflik persimpangan. Kecelakaan dapat terjadi akibat kendaraan yang melaju lurus dengan kendaraan yang membelok ke kiri atau ke kanan dan sesama kendaraan yang bergerak lurus (Kweon, 2007). Selain itu, berbagai jenis RLR dapat menyebabkan tingkat keparahan yang berbeda-beda.

Berdasarkan latar belakang diatas dapat disimpulkan bahwa salah satu faktor utama penyebab kecelakaan pada simpang bersinyal adalah pelanggaran saat merah (RLR). Untuk mengkaji perilaku pada RLR perlu dilakukan langkah awal yaitu identifikasi simpang bersinyal yang rawan kecelakaan. Pada penelitian ini dilaksanakan langkah pertama yang mengacu pada (planning component) yang terdiri dari pengumpulan data, identifikasi daerah rawan kecelakaan. Pada penelitian ini hanya akan dilakukan tahapan awal (planning component) langkah selanjutnya menjadi kelanjutan dari penelitian ini. 


\section{LITERATURE REVIEW}

\section{Kecelakaan Lalu Lintas}

Menurut anonim (2014), kecelakaan merupakan suatu kejadian di jalan yang tidak didugaduga dan tidak disengaja yang melibatkan kendaraan dengan atau tanpa pengguna jalan lain yang mengakibatkan korban manusia dan/atau kerugian material. Menurut World Health Organization (WHO) dalam Khairun (2014), memperkirakan pada tahun 2030 kecelakaan lalu lintas menjadi penyebab kematian nomor 5 (lima) di dunia setelah jantung, stroke, paru-paru dan infeksi saluran pernapasan. Hal tersebut memicu beberapa teknisi untuk menciptakan perencanaan-perencanaan yang dapat diaplikasikan untuk meminimalisir sistem operasional lalu lintas seperti yang tercantum dalam Rencana Umum Nasional Keselamatan (RUNK) yang menjadi pilar aksi keselamatan lalu lintas, yaitu manajemen keselamatan jalan, infrastruktur, jalan yang berkeselamatan, perilaku pengguna jalan dan perawatan pasca kecelakaan.

\section{Faktor Penyebab Kecelakaan Lalu Lintas}

Menurut Nurwanti (2001) dari seluruh kecelakaan yang terjadi di jalan raya khususnya di Indonesia, faktor kelalaian manusia (human error) memiliki kontribusi paling tinggi, yaitu mencapai antara 80-90 persen dibandingkan dengan faktor ketidaklayakan sarana kendaraan yang berkisar antara 5-10 persen maupun akibat kerusakan infrastruktur jalan antara 10-20 persen. Dengan demikian faktor-faktor penyebab kecelakaan lalu lintas terutama pada simpang adalah faktor internal yaitu para pemakai jalan itu sendiri dan faktor eksternal yaitu fungsi dan kondisi geometri yang tersedia.

\section{Red Light Running (RLR)}

Kecelakaan lalu lintas Red Light Running (RLR) didefinisikan sebagai kejadian bahwa pengemudi secara sengaja atau tidak sengaja melanggar lampu merah di persimpangan yang mengakibatkan kecelakaan atau konflik dengan pengemudi lain yang memiliki hak berjalan (Baratian-Ghorghi dkk. 2016). Tiga jenis perilaku RLR yang sering terjadi di persimpangan yaitu pengemudi berniat melanggar lampu merah dengan sengaja, pengemudi mengambil keputusan keberangkatan pada saat sinyal kuning dan pengemudi gagal melihat lampu lalu lintas karena ketidak lancaran visibilitas sinyal (Zhang, et al., 2018).

Pelanggaran RLR merupakan bentuk pelanggaran yang paling banyak dijumpai pada simpang bersinyal dan menjadi salah satu faktor dominan penyebab kecelakaan lalu lintas di persimpangan. Kecelakaan akibat RLR telah berkontribusi paling banyak menyebabkan kecelakaan dengan kategori luka berat hingga kematian (Young dkk., 2013; Polders dkk., 2015; Jahangiri dkk., 2016; Ren dkk., 2016). Sebagai contoh, di Thailand pada Tahun 2015 dilaporkan 1702 kecelakaan lampu merah di persimpangan atau 1,96\% dari semua kecelakaan yang dilaporkan polisi disebabkan oleh pengemudi melanggar lampu merah (Kanitpong dkk., 2015; Jensupakarn dkk., 2018). Jenis kecelakaan RLR dapat diklasifikasikan berdasarkan gerakan kendaraan masuk ke area konflik persimpangan. Kecelakaan dapat terjadi akibat kendaraan yang melaju lurus dengan kendaraan yang membelok ke kiri atau ke kanan dan sesama kendaraan yang bergerak lurus (Kweon, 2007). Selain itu, berbagai jenis RLR dapat menyebabkan tingkat keparahan yang berbedabeda. 


\section{Penentuan Lokasi Rawan Kecelakaan}

Highway Safety Improvement Program di dalam Highway Safety Manual (HSM, 2010) menjelaskan prosedur peningkatan keselamatan jalan dengan mengacu pada (planning component) yang terdiri dari pengumpulan data, identifikasi daerah rawan kecelakaan. Kelanjutan dari tahapan ini adalah melakukan tinjauan langsung di lapangan untuk in deep study (kajian mendalam terhadap potensi konflik dan perilakunya). Langkah selanjutnya mengacu pada hasil in-depth study dilakukan penerapan penanganan (implementation component) yaitu melakukan jadwal dan melaksanakan perbaikan keselamatan dan langkap ketiga mengacu pada (evaluation component) yaitu melakukan evaluasi perbaikan keselamatan lalu lintas akibat pelanggaran RLR. Pd T-09-2004-B (2004) menyebutkan identifikasi 10-15 lokasi rawan kecelakaan terburuk ditentukan dengan berdasarkan frekuensi kecelakaan tertinggi dari data kecelakaan selama tiga tahun berturut-turut atau sekurang-kurangnya 2 (dua) tahun berturut-turut. Teknik identifikasi lokasi kecelakaan tersebut antara lain:

1. Lokasi kecelakaan terburuk pada jaringan jalan perkotaan diidentifikasikan dengan sistem noda berdasarkan nomor persimpangan dan sistem Link berdasarkan nomor ruas jalan.

2. Lokasi kecelakaan pada ruas jalan antar kota untuk mengeluarkan lokasi ruas jalan terburuk pada ruas jalan antar kota dapat dilakukan dengan sistem nomor ruas dan $\mathrm{Km}$ melalui perangkat lunak Sistem-3L.

Dikutip kembali oleh Reza Agustian (2012), metode tingkat frekuensi kecelakaan lalu lintas dihitung berdasarkan banyaknya jumlah kecelakaan kendaraan per kilometer yang terjadi dari setiap perjalanan dalam waktu satu tahun. Metode frekuensi kecelakaan lalu lintas dihitung berdasarkan banyaknya jumlah kecelakaan lalu lintas yang terjadi pada setiap jalan dalam waktu satu tahun. Setelah mengumpulkan dan mengelola data kecelakaan lalu lintas tersebut minimal selama tiga tahun terakhir, selanjutnya dilakukan pemeringkatan untuk setiap jalan yang mengalami kecelakaan lalu lintas berdasarkan frekuensi seberapa sering terjadinya kecelakaan pada jalan tersebut.

\section{Identifikasi Simpang Rawan Kecelakaan}

Menurut Pd T-09-2004-B (2004), lokasi rawan kecelakaan adalah suatu lokasi dimana angka kecelakaan tinggi dengan kejadian kecelakaan berulang dalam suatu ruang dan rentang waktu yang relatif sama yang diakibatkan oleh suatu penyebab tertentu.

\section{Metode Tingkat Kecelakaan Lalu Lintas}

Menurut Pd T-09-2004-B (2004), teknik pemeringkatan lokasi kecelakaan dapat dilakukan dengan pendekatan tingkat kecelakaan dan pembobotan berdasarkan nilai kecelakaan.

\section{Tingkat Kecelakaan}

Perhitungan tingkat kecelakaan lalu lintas pada lokasi persimpangan menggunakan rumus:

$$
\mathrm{Tk}=\frac{\mathrm{Fk} \mathrm{x} 10^{8}}{\mathrm{~V} \times \mathrm{n} \times 0,1 \times 365},(100 \mathrm{JPKP})
$$

Dimana Tk adalah tingkat kecelakaan dalam 100 JPKP, Fk adalah frekuensi kecelakaan di persimpangan untuk $\mathrm{n}$ tahun data, $\mathrm{V}$ adalah volume lalu lintas persimpangan, $\mathrm{N}$ adalah jumlah tahun data dan 100JPKP adalah satuan tingkat kecelakaan (kecelakaan/Seratus Juta Perjalanan Kendaraan Per-kilometer). 


\section{Pemeringkatan Dengan Pembobotan Tingkat Kecelakaan Menggunakan Konversi Biaya Kecelakaan}

Memanfaatkan perbandingan nilai moneter dari biaya kecelakaan dengan perbandingan :

$$
\mathrm{M}: \mathrm{B}: \mathrm{R}: \mathrm{K}=\mathrm{M} / \mathrm{K}: \mathrm{B} / \mathrm{K}: \mathrm{R} / \mathrm{K}: 1
$$

Dimana $\mathrm{M}$ adalah meninggal dunia, $\mathrm{B}$ adalah luka berat, $\mathrm{R}$ adalah luka ringan dan $\mathrm{K}$ adalah kecelakaan dengan kerugian materi. Dengan menggunakan angka ekuivalen kecelakaan dengan sistem pembobotan yang mengacu kepada biaya kecelakaan :

$$
\mathrm{M}: \mathrm{B}: \mathrm{R}: \mathrm{K}=12: 3: 3: 1
$$

Metode tingkat keparahan kecelakaan lalu lintas atau Equivalent Property Damage Only (EPDO) dihitung berdasarkan perkiraan biaya kerusakan properti atau Property Damage Only (PDO) yang ditimbulkan dari kecelakaan lalu lintas tersebut. Untuk mencari nilai tingkat keparahan kecelakaan lalu lintas digunakan rumus:

$$
\mathrm{EPDO}=\mathrm{M}: \mathrm{B}: \mathrm{R}: \mathrm{K}=12: 6: 3: 1
$$

\section{METODOLOGI}

Tahapan dalam pelaksanaan penelitian dimulai dengan penyusunan rencana pengumpulan data dan mempersiapkan alat-alat untuk pengumpulan data tersebut. Untuk pengumpulan data dibagi menjadi dua macam, yaitu data primer dan data sekunder. Data yang digunakan dalam penelitian ini bersumber dari data primer yaitu data yang dikumpulkan dengan pengumpulan langsung ke lokasi tinjauan. Data sekunder diperoleh dari instansi terkait yaitu data dari Satlantas Polresta Kota Banda Aceh.

\section{Data primer}

Data primer adalah data hasil pengamatan langsung oleh peneliti sebagai bahan acuan untuk mengetahui secara khusus terhadap permasalahan yang sering terjadi di ibukota Aceh ini. Data primer dapat berupa data geometrik jalan, volume lalu lintas yang diamati dengan menggunakan kamera digital. Pelaksanaan penelitian ini meliputi :

1. Melakukan pengamatan dan pengukuran geometrik jalan dengan mendata seberapa lebar tiap-tiap ruas simpang yang mengalami kepadatan;

2. Data volume lalu lintas diperoleh dengan mempertimbangkan faktor-faktor jumlah kendaraan dan arah pergerakan terhadap waktu kapan jam puncak terjadi. Penelitian ini dilakukan selama 2 (dua) minggu namun hanya dilakukan pengamatan untuk 5 (lima) hari yang menjadi prioritas yaitu Senin, Selasa, Rabu, Kamis dan Senin dengan anggapan hari lain dianggap relevan. waktu pengamatan pada saat pagi hari pukul 7:00-8:00, siang pukul 12.00-13.00 dan sore pukul 17.00-18.00.

3. Dalam pengumpulan data ini, jumlah kendaraan yang telah diklasifikasikan jenis-jenis kendaraannya dihitung secara manual dibantu oleh beberapa orang teman selama 60 menit setiap waktu pengamatan sehingga diperoleh data volume lalu lintas tiap jam (smp/jam).

\section{Data Sekunder}

Data sekunder adalah data yang digunakan sebagai pelengkap dalam penelitian ini yaitu berupa data-data kecelakaan yang dikeluarkan secara resmi oleh instansi terkait yaitu Kepolisian resor kota (Polresta) Banda Aceh, peta Aceh, peta Kota Banda Aceh dan peta 
lokasi. Data tersebut berupa data kecelakaan untuk 3 (tiga) tahun terakhir yaitu 2013, 2014 dan 2015 yang berisi tentang jumlah jiwa yang mengalami luka ringan, luka berat dan meninggal dunia bahkan kerugian materi.

\section{Pengolahan Data}

Pengolahan data dilakukan setelah hasil pengumpulan data terkumpul. Pengolahan data ini berdasarkan Prosedur Penanganan Lokasi Rawan Kecelakaan Departemen Permukiman dan Prasarana Wilayah (Pd-T-09-2004-B). Dalam pengolahan data perhitungan dilakukan terhadap volume lalu lintas, pemeringkatan lokasi kecelakaan. Perhitungan pemeringkatan lokasi kecelakaan dilakukan dengan pendekatan tingkat kecelakaan dan pembobotan berdasarkan nilai kecelakaan. Perhitungan pemeringkatan lokasi kecelakaan diperoleh dari tingkat kecelakaan (persamaan 1) dan pemeringkatan pembobotan menggunakan konversi biaya kecelakaan. Untuk mendapatkan rumus tersebut digunakan persamaan 2, persamaan 3 dan persamaan 5. Perangkingan awal dilakukan untuk mengidentifikasi lokasi kecelakaan lalu lintas terburuk berdasarkan frekuensi seberapa sering terjadinya kecelakaan pada simpang di Banda Aceh selama 3 (tiga) tahun terakhir. Dari seluruh lokasi yang terdata oleh Satlantas Polresta Kota Banda Aceh diambil 9 (sembilan) lokasi kecelakaan terburuk untuk dijadikan lokasi penelitian. Selanjutnya dilakukan pemeringkatan lokasi kecelakaan pada simpang dengan perhitungan tingkat kecelakaan berdasarkan volume lalu lintas yang diperoleh dari data primer. Kemudian dilakukan penandaan setiap titik-titik yang diidentifikasi sebagai lokasi rawan kecelakaan.

\section{HASIL DAN PEMBAHASAN}

\section{Geometrik dan Volume Lalu lintas}

Berdasarkan sembilan lokasi simpang kecelakaan yang telah dilakukan penelitian, maka hasil pengukuran geometrik simpang yang diperoleh dengan melakukan pengukuran langsung ke lapangan dapat dilihat pada Tabel 1. Tabel 1 memperlihatkan bahwa dari 9 simpang yang ditinjau rata-rata memiliki lebar lengan pendekat $5-6,5 \mathrm{~m}$ dengan jenis simpang bersinyal 4 lengan atau 4 fase.

Tabel 1. Hasil pengukuran geometrik simpang dan volume lalu lintas

\begin{tabular}{clccccc}
\hline No & Nama Simpang & $\begin{array}{c}\text { Jenis } \\
\text { Simpang }\end{array}$ & Kode Tipe & $\begin{array}{c}\text { Lebar Lajur } \\
(\mathbf{m})\end{array}$ & $\begin{array}{c}\text { Lebar } \\
\text { Median (m) }\end{array}$ & $\begin{array}{c}\text { Volume } \\
(\text { SMP/Jam) }\end{array}$ \\
\hline 1 & Simpang Dodik** & 4 & $424 \mathrm{M}$ & 6,5 & 2,5 & 1.837 \\
\hline 2 & Simpang Tujuh* & 7 & 722 & 5 & - & 2.114 \\
\hline 3 & Simpang Jambo Tape** & 4 & $424 \mathrm{M}$ & 6,5 & 2,5 & 2.196 \\
\hline 4 & Simpang Pasar Aceh* & 4 & 422 & 8 & - & 1.892 \\
\hline 5 & Simpang AMD** & 4 & 444 & 6,5 & - & 1.836 \\
\hline 6 & Simpang Mesra* & 3 & $324 \mathrm{M}$ & 6,5 & 2,5 & 1.806 \\
\hline 7 & Simpang MAN Model** & 4 & 422 & 6 & - & 1.826 \\
\hline 8 & Simpang Tiga** & 4 & $424 \mathrm{M}$ & 4,5 & 2 & 2.202 \\
\hline 9 & Simpang Lamlagang** & 3 & 322 & 3 & - & 1.443 \\
\hline
\end{tabular}

Note: *Simpang tak bersinyal, **Simpang bersinyal 
Tabel 2. Rekapitulasi data kecelakaan pada simpang tahun 2013-2015 di Banda Aceh

\begin{tabular}{clcccc}
\hline \multirow{2}{*}{ No } & \multirow{2}{*}{ Uraian } & \multicolumn{3}{c}{ Tahun } & \multirow{2}{*}{ Total } \\
\cline { 3 - 5 } & & $\mathbf{2 0 1 3}$ & $\mathbf{2 0 1 4}$ & $\mathbf{2 0 1 5}$ & \\
\hline 1 & Jumlah Kecelakaan & 15 & 14 & 19 & 48 \\
\hline 2 & Jumlah Kecelakaan Meninggal Dunia & 1 & 7 & 4 & 12 \\
\hline 3 & Jumlah Kecelakaan Luka Berat & 24 & 21 & 24 & 69 \\
\hline 4 & Jumlah Kecelakaan Luka Ringan & 23 & 20 & 22 & 65 \\
\hline 5 & Jumlah Kerugian Materi & 19 & 29 & 34 & 82 \\
\hline
\end{tabular}

\section{Distribusi Data Kecelakaan}

Berdasarkan data dari Satlantas Kota Banda Aceh untuk kecelakaan pada simpang dalam 3 tahun berturut-turut yaitu 2013 sampai 2015. Jumlah kecelakaan yang terjadi pada tahun 2014 menurun namun pada tahun 2015 kembali meningkat meskipun tidak signifikan. Tetapi jika ditinjau dari jenis kecelakaan dan kerugian materi tahun 2015 merupakan tingkat kecelakaan yang tinggi dibanding dengan tahun-tahun sebelumnya. Rekapitulasi kerugian materi kecelakaan pada simpang bersinyal Tahun 2013-2015 di Banda Aceh memperlihatkan pada tahun 2013 sebesar Rp. 19.000.000,- tahun 2014 sebesar Rp. 29.000.000,- dan tahun 2015 sebesar Rp. 34.000.000,-. Total kerugian materi selama tiga tahun (2013-2015) sebesar Rp 82.000.000,-.

\section{Analisis Berdasarkan Frekuensi Kecelakaan Lalulintas}

Rekapitulasi analisis berdasarkan frekuensi kecelakaan dapat dilihat pada Tabel 3 . Berdasarkan Tabel 3 jumlah kecelakaan yang 3 tertinggi untuk simpang bersinyal adalah Simpang Dodik, Simpang Jambo Tape dan Simpang AMD.

Tabel 3. Hasil rekapitulasi data kecelakaan selama 3 tahun di Banda Aceh

\begin{tabular}{clccccc}
\hline \multirow{2}{*}{ No } & & Nama Simpang & \multicolumn{5}{c}{ Total per-Simpang } \\
\cline { 3 - 6 } & & JK & MD & LB & LR & KM (Rp) \\
\hline 1 & Simpang Dodik** & 5 & 5 & 8 & 8 & 20.650 .000 \\
\hline 2 & Simpang Tujuh* & 8 & 2 & 10 & 6 & 20.250 .000 \\
\hline 3 & Simpang Jambo Tape** & 5 & 3 & 6 & 9 & 9.250 .000 \\
\hline 4 & Simpang Pasar Aceh* & 7 & 1 & 9 & 6 & 7.200 .000 \\
\hline 5 & Simpang AMD** & 3 & 1 & 6 & 5 & 5.420 .000 \\
\hline 6 & Simpang Mesra* & 5 & 0 & 6 & 9 & 4.150 .000 \\
\hline 7 & Simpang MAN Model** & 3 & 0 & 6 & 3 & 3.800 .000 \\
\hline 8 & Simpang Tiga** & 4 & 0 & 8 & 10 & 3.500 .000 \\
\hline 9 & Simpang Lamlagang** & 3 & 0 & 5 & 2 & 2.900 .010 \\
\hline Keterangan: $\quad$ JK (Jumlah Kecelakaan); MD (Meninggal Dunia); LB (Luka Berat); LR (Luka Ringan);
\end{tabular}

Note: *Simpang tak bersinyal, **Simpang bersinyal 


\section{Analisis Berdasarkan Tingkat Kecelakaan}

Teknik pemeringkatan lokasi kecelakaan dilakukan dengan pendekatan tingkat kecelakaan dan pembobotan berdasarkan nilai kecelakaan. Pada analisis tingkat kecelakaan (TK), akan dijelaskan perhitungan secara per tahun dengan data yang telah diperoleh dari pengolahan data primer dan pengolahan data sekunder seperti data jumlah kecelakaan (Fk), jangka waktu analisis (n), dan Volume Lalu Lintas Persimpangan (VLLP). Berdasarkan Gambar 1 perangkingan simpang kecelakaan pada tahun 2015 dengan nilai tertinggi sebesar untuk simpang bersinyal adalah simpang Dodik 994 kecelakaan/100JPKP, Simpang Jambo Tape sebesar 831 kecelakaan/100JPKP dan Simpang Lamlagang sebesar 633 kecelakaan/ 100JPKP.

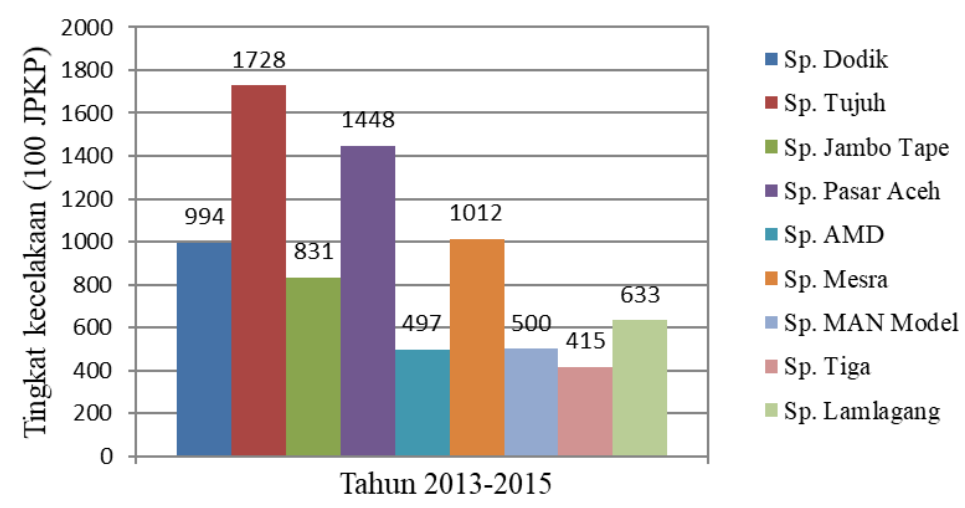

Gambar 1. Tingkat Kecelakaan per 100JPKP

\section{Analisis Perhitungan dengan Metode tingkat Keparahan}

Metode tingkat keparahan kecelakaan lalu lintas dihitung berdasarkan biaya kerusakan properti sesuai dengan rumus EPDO (equivalent properties damage only). Kecelakaan yang diklasifikasikan menurut kelasnya yaitu meninggal dunia, luka berat, luka ringan dan kerugian materi yang kemudian dikalikan dengan angka ekuivalen kecelakaan.

Tabel 4. Nilai pembobotan berdasarkan EPDO

\begin{tabular}{|c|c|c|c|c|c|c|c|c|}
\hline \multirow{2}{*}{ No. } & \multirow{2}{*}{ Nama simpang } & \multirow{2}{*}{$\begin{array}{l}\text { Total } \\
\text { Kec. }\end{array}$} & \multicolumn{5}{|c|}{ EPDO } & \multirow{2}{*}{ Rank. } \\
\hline & & & $12 \times M$ & $6 \times \mathbf{B}$ & $\mathbf{3 x R}$ & $1 \mathbf{x K}$ & Total & \\
\hline 1 & Simpang Dodik** & 4 & 60 & 48 & 24 & 20,65 & 153 & 1 \\
\hline 2 & SimpangTujuh* & 5 & 24 & 60 & 18 & 20,25 & 122 & 2 \\
\hline 3 & Simpang Jambo Tape ${ }^{* *}$ & 4 & 36 & 36 & 27 & 9,25 & 108 & 3 \\
\hline 4 & Simpang Pasar Aceh* & 5 & 12 & 54 & 18 & 7,2 & 91 & 4 \\
\hline 5 & Simpang $A M D^{* *}$ & 3 & 12 & 36 & 15 & 5,42 & 68 & 5 \\
\hline 6 & Simpang Mesra* & 5 & 0 & 36 & 27 & 4,15 & 67 & 6 \\
\hline 7 & Simpang MAN Model** & 3 & 0 & 36 & 9 & 3,8 & 49 & 8 \\
\hline 8 & Simpang Tiga* & 4 & 0 & 48 & 30 & 3,5 & 82 & 9 \\
\hline 9 & Simpang Lamlagang** & 3 & 0 & 30 & 6 & 2,9 & 39 & 10 \\
\hline
\end{tabular}

Keterangan: $\quad$ M (Meninggal dunia); B (Luka Berat); R (Luka Ringan); K (Kerugian Materi) EPDO (Equivalent Properties Damage Only)

Note: *Simpang tak bersinyal, **Simpang bersinyal 
Berdasarkan Tabel 4 tingkat keparahan kecelakaan lalu lintas pada simpang bersinyal yang berada pada rangking 1 adalah Simpang Dodik dengan nilai total sebesar 153, rangking ke2 dengan nilai 108 adalah pada Simpang Jambo Tape dan pada Simpang AMD berada pada rangking ke-3 dengan nilai total sebesar 68 EPDO.

\section{Penentuan Prioritas dan Pembahasan}

Setelah dianalisis berdasarkan metode frekuensi kecelakaan, metode tingkat kecelakaan, dan metode tingkat keparahan terhadap data kecelakaan lalu lintas selama tiga tahun terakhir yaitu 2013-2015, maka diperoleh beberapa faktor yang mempengaruhi analisa perhitungan yaitu frekuensi kecelakaan lalu lintas, volume lalu lintas, lebar simpang yang ditinjau dan jumlah korban baik yang meninggal dunia, luka berta, luka ringan maupun kerugian materi serta pengguna jalan itu sendiri. Berdasarkan hasil dari analisis dengan menggunakan metode frekuensi kecelakaan lalu lintas (Tabel 5), simpang yang memiliki peringkat tertinggi Simpang Dodik, Simpang Jambo Tape dan Simpang AMD. Oleh karena itu, ketiga simpang tersebut perlu mendapatkan penanganan terlebih dahulu menurut perangkingan secara frekuensi.

Tabel 5. Perangkingan simpang bersinyal rawan kecelakaan berdasarkan metode frekuensi

\begin{tabular}{clccccc}
\hline \multirow{2}{*}{ No. } & \multirow{2}{*}{ Nama Simpang } & \multicolumn{5}{c}{ Total per-Simpang } \\
\cline { 3 - 7 } & & JK & MD & LB & LR & Kerugian Materi \\
\hline 1 & Sp. Dodik & 5 & 5 & 8 & 8 & $\operatorname{Rp~20.650.000}$ \\
\hline 2 & Sp. Jambo Tape & 5 & 3 & 6 & 9 & $\operatorname{Rp~} 9.250 .000$ \\
\hline 3 & Sp. AMD & 3 & 3 & 6 & 5 & $\operatorname{Rp~5.420.000}$ \\
\hline
\end{tabular}

Tabel 6. Simpang bersinyal yang direkomendasi untuk prioritas kajian RLR

\begin{tabular}{clccc}
\hline \multirow{2}{*}{ No } & \multirow{2}{*}{ Nama Simpang } & \multicolumn{3}{c}{ Indikator Nilai (2013-2015) } \\
\cline { 3 - 5 } & & Frekuensi Kecelakaan & Tingkat Kecelakaan & Tingkat Keparahan \\
\hline 1 & Simpang Dodik & 5 & 944 & 152 \\
\hline 2 & Simpang Jambo Tape & 5 & 831 & 108 \\
\hline 3 & Simpang AMD & 3 & 497 & 68 \\
\hline
\end{tabular}

Dengan menggunakan beberapa metodologi diatas disimpulkan tiga simpang bersinyal yang perlu dilakukan kajian mendalam tentang pelanggaran lalu lintas pada simpang bersinyal. Ketiga simpang yang direkomendasikan berpotensi rawan terhadap pelanggaran RLR adalah Simpang Dodik, Simpang Jambo Tape dan Simpang AMD. Kriteria pemilihan berdasarkan analisis frekuensi kecelakaan, kerugian harta benda (EPDO), tingkat kecelakaan dan tingkat keparahan kecelakaan. Untuk ke tiga simpang tersebut direkomendasikan untuk dilakukan prioritas kajian yang mendalam (in -depth study) untuk investigasi perilaku RLR penentuan penanganan (implementation component) yaitu melakukan jadwal dan melaksanakan perbaikan keselamatan dan langkap ketiga mengacu pada (evaluation component) yaitu melakukan evaluasi perbaikan keselamatan lalu lintas akibat pelanggaran RLR. 


\section{KESIMPULAN}

Berdasarkan hasil dari analisis untuk penentuan lokasi prioritas penanganan pada simpang bersinyal yang berpotensi besar terjadi pelanggaran RLR di Banda Aceh dengan data tahun 2013-2015 dengan menggunakan tiga metode, yaitu metode frekuensi kecelakaan, metode tingkat kecelakaan, dan metode tingkat keparahan kecelakaan (EPDO) maka dapat disimpulkan sebagai berikut:

1. Simpang Dodik merupakan simpang yang pertama diprioritaskan untuk mendapatkan penanganan terlebih dahulu dengan nilai frekuensi kecelakaan yang diperoleh $=5$, tingkat kecelakaan $(\mathrm{TK})=994$ kecelakaan/100JPKP dan tingkat keparahan kecelakaan $(\mathrm{EPDO})=152$.

2. Simpang Jambo Tape merupakan simpang kedua yang diprioritaskan untuk mendapatkan penanganan terlebih dahulu dengan nilai frekuensi kecelakaan yang diperoleh $=5$, tingkat kecelakaan $(\mathrm{TK})=831$ kecelakaan/100JPKP dan tingkat keparahan kecelakaan $($ EPDO $)=108$.

3. Sedangkan Simpang Dodik merupakan simpang yang ketiga diprioritaskan untuk mendapatkan penanganan terlebih dahulu dengan nilai frekuensi kecelakaan yang diperoleh $=3$, tingkat kecelakaan $(\mathrm{TK})=497$ kecelakaan/100JPKP dan tingkat keparahan kecelakaan $($ EPDO $)=497$.

4. Untuk ke tiga simpang tersebut direkomendasikan untuk dilakukan prioritas kajian yang mendalam (in-depth study) untuk investigasi perilaku RLR penentuan penanganan (implementation component) yaitu melakukan jadwal dan melaksanakan perbaikan keselamatan dan langkap ketiga mengacu pada (evaluation component) yaitu melakukan evaluasi perbaikan keselamatan lalu lintas akibat pelanggaran RLR

\section{UCAPAN TERIMA KASIH}

Ucapan terima kasih kepada Korlantas Polri atas pendanaan penelitian ini melalui Hibah Traffic Accident Research Centre (TARC) tahun 2018. Juga diucapkan terima kasih kepada Kepolisian Resor Kota Banda Aceh yang telah mengizinkan penggunaan data kecelakaan pada penelitian ini.

\section{DAFTAR PUSTAKA}

Agustian, Reza. 2012. Analisis Prioritas Penanganan Segmen Rawan Kecelakaan (Road Hazaard) untuk Ruas Jalan Rawan Kecelakaan di Kota Banda Aceh. Tugas Akhir. Unsyiah.

Anonim. 2004. Penanganan Lokasi Rawan Kecelakaan Departemen Permukiman dan Prasarana Wilayah. Jakarta.

Baratian-Ghorghi, F. Zhou, H.; Zech, W.C. 2016. Red-light running traffic violations: A novel time-based method for determining a fine structure. Transp. Res. Part A Policy Pract. 93, 55-65

Jahangiri, A., Rakha, H., Dingus, T.A. 2016. Red-light running violation prediction using observational and simulator data. Accid. Anal. Prev. 96, 316-328.

Jensupakarn, A., Kanitpong, K. 2018. Influences of motorcycle rider and driver characteristics and road environment on red light running behavior at signalized intersections. Accid. Anal. Prev. 113, 317-324. 
Khairun, dkk. 2014. Persepsi Masyarakat Terhadap Keselamatan Lalu Lintas di Jalan Teuku Umar Kota banda Aceh. Jurnal Teknik Sipil Pascasarjana Universitas Syiah Kuala, Volume (3):2.

Kanitpong, K., Jensupakarn, A., Jensupakarn, P., Jiwattanakulpaisarn, P. 2015. National Statistics of Traffic Accident in Thailand 2015; ThaiRoads Foundation: Bangkok, Thailand.

Kweon, Y.J. 2007. Development of a Safety Evaluation Procedure for Identifying HighRisk Signalized Intersections in the Virginia Department of Transportation's Northern Virginia District; Crash Rates; Virginia Transportation Research Council: Charlottesville, VA, USA.

McCarthy, N. The Most Dangerous US Cities for Red-Light Running. 2015. Available online: https://www.statista.com/chart/3717/red-light-running

Nurwanti. 2001. Klasifikasi dan Faktor-Faktor Penyebab Kecelakaan Lalu Lintas. Tugas Akhir. Universitas Negeri Malang.

Polders, E.; Cornu, J., De, C.T., Daniels, S., Brijs, K., Brijs, T., Hermans, E., Wets, G. 2015. Drivers' behavioral responses to combined speed and red light cameras. Accid. Anal. Prev. 81, 153-166.

Ren, Y., Wang, Y., Wu, X., Yu, G., Ding, C. 2016. Influential factors of red-light running at signalized intersection and prediction using a rare events logistic regression model. Accid. Anal. Prev. 95, 266-273..

Saleh, S.M., Sugiarto, S., Hilal, A., Ariansyah, D. 2017. A study on the traffic impact of the road corridors due to flyover construction at Surabaya intersection, Banda Aceh of Indonesia. AIP Conference Proceedings. AIP Conf. Proc. 1903.

Sugiarto, S., Limanond, T., 2013. Impact of on-street parking on urban arterial performance: A quantitative study on travel speed and capacity deterioration. Aceh International Journal of Science and Technology, 2(1): 63-69.

Young, K.L., Salmon, P.M., Lenné, M.G. 2013. At the cross-roads: An on-road examination of driving errors at intersections. Accid. Anal. Prev. 58, 226-234.

Zhang Y., Yan X., Li X., Wu J., Dixit VV. 2018. Red-Light-Running Crashes' Classification, Comparison, and Risk Analysis Based on General Estimates System (GES) Crash Database, International Journal of Environmental Research and Public Health, 15, 1290. 